\title{
Deformation microstructures and tensile properties of an austenitic stainless steel subjected to multiple warm rolling
}

\author{
Z. Yanushkevich, A. Lugovskaya, A. Belyakov*, R. Kaibyshev \\ Belgorod State University, Pobeda 85, Belgorod 308015, Russia
}

\section{A R T I C L E I N F O}

\section{Article history:}

Received 10 March 2016

Received in revised form

30 April 2016

Accepted 2 May 2016

Available online 3 May 2016

Keywords:

Mechanical characterization

Austenite

Thermomechanical processing

Grain refinement

Yield strength

\begin{abstract}
A B S T R A C T
The deformation microstructures of a 316L-type austenitic stainless steel subjected to multiple bar rolling to a total strain of 2 at temperatures of 773-1173 K and their effect on the mechanical properties at ambient and elevated temperatures were studied. The multiple warm rolling was accompanied by significant grain refinement. The finally evolved transverse grain size decreased from $3.4 \mu \mathrm{m}$ to $0.85 \mu \mathrm{m}$ with a decrease in the rolling temperature from $1173 \mathrm{~K}$ to $773 \mathrm{~K}$. The warm rolled steel samples were characterized by significantly increased strength properties. The strengthening was studied by tensile tests at ambient and elevated temperatures. A decrease in the rolling temperature from $1173 \mathrm{~K}$ to $773 \mathrm{~K}$ increased the yield strength from $720 \mathrm{MPa}$ to $945 \mathrm{MPa}$ or from $395 \mathrm{MPa}$ to $470 \mathrm{MPa}$ at room temperature and $973 \mathrm{~K}$, respectively. The strengthening obeyed Hall-Petch relationship with a grain size strengthening coefficient decreased from $410 \mathrm{MPa} \mu \mathrm{m}^{0.5}$ at room temperature to $140 \mathrm{MPa} \mu \mathrm{m}^{0.5}$ at $973 \mathrm{~K}$.
\end{abstract}

(c) 2016 Elsevier B.V. All rights reserved.

\section{Introduction}

Austenitic stainless steels are one of the most widely used structural materials because of their beneficial combination of mechanical, technological and functional properties [1]. A common disadvantage of austenitic stainless steels is their relatively low yield strengths of 200-400 MPa, which limits their usage in critical applications [2]. Generally, mechanical properties and, in particular, an yield strength of metallic materials depend significantly on their microstructures, which in turn can be controlled by thermo-mechanical treatments. Regarding the strength of structural steels and alloys, substantial strengthening can be obtained by structural refinement, which is achieved by a decrease in the grain size and can be expressed by Hall-Petch relationship [37].

Large strain deformations under conditions of warm to hot working, which are accompanied by the development of dynamic recrystallization (DRX), are powerful tool for processing the austenitic stainless steels with desirable microstructures [8-10]. The required grain size distribution can be developed directly during plastic working under appropriate conditions. Depending on deformation conditions, the austenitic stainless steels exhibit different DRX behaviors [11]. The discontinuous DRX takes place in

\footnotetext{
* Corresponding author.

E-mail address: belyakov@bsu.edu.ru (A. Belyakov).
}

cyclic manner under hot working conditions, when the new grains repeatedly nucleate due to local migration, i. e. bulging, of the grain boundaries and then the recrystallizing nuclei grow at expense of work hardened surroundings [9]. On the other hand, the new grains evolve as a result of progressive increase in misorienations among the strain-induced subboundaries up to typical values of high-angle grain boundaries in the case of continuous DRX under warm working conditions [9]. The mean grain size that evolve at sufficiently large strains depends sensitively on the deformation conditions and can be expressed by power law functions of flow stress with grain size exponents of -0.7 and -0.4 for discontinuous and continuous dynamic recrystallization domains, respectively. These dependencies suggest that significant grain refinement should be expected during large strain deformation under high flow stresses, which can be realized under conditions of warm working at relatively low temperatures. However, in contrast to hot working, which has been widely using for steel processing, warm working is rarely involved in the modern thermo-mechanical techniques dealing with production of austenitic stainless steels.

The aim of the present paper is to report the results of our current investigations on the deformation microstructures and tensile properties of a 316L-type austenitic stainless steel subjected to caliber rolling under conditions of warm to hot working at temperatures of $0.45-0.7$ of the melting point. The paper is particularly focused on the effect of rolling temperature on the 
yield strength of the steel at ambient and elevated temperatures.

\section{Experimental}

A 316L-type austenitic stainless steel, Fe $-0.04 \% \mathrm{C}-0.4 \% \mathrm{Si}-$ $1.7 \% \mathrm{Mn}-17.3 \% \mathrm{Cr}-10.7 \% \mathrm{Ni}-2.0 \% \mathrm{Mo}-0.04 \% \mathrm{P}-0.05 \% \mathrm{~S}-0.09 \% \mathrm{~V}-$ $0.04 \% \mathrm{Ti}-0.05 \% \mathrm{Nb}-0.4 \% \mathrm{Cu}-0.19 \% \mathrm{Co}$ (all in mass\%), was hot forged at $1373 \mathrm{~K}$ followed by air cooling. The starting material was characterized by an average grain size of $21 \mu \mathrm{m}$ and an average dislocation density of $2.3 \times 10^{12} \mathrm{~m}^{-2}$. The rod samples were heated in a muffle furnace to desired temperature in the range of $773-1173 \mathrm{~K}(0.45-0.7 \mathrm{Tm})$. Then, the multiple bar rolling was carried out with a pass strain of 0.25 to a total cumulative strain of 2 followed by water quenching. The steel rods were reheated in about $5 \mathrm{~min}$ to the processing temperature after each 0.5 strain increment.

Structural observations were performed on the sections parallel to the rolling axis, using a Quanta 600 FEG scanning electron microscope equipped with an electron back scattering diffraction pattern (EBSP) analyser incorporating an orientation imaging microscopy (OIM) system. The OIM images were subjected to clean up procedure setting a minimal confidence index of 0.1 . The mean grain size was evaluated on the OIM micrographs as average distance between high-angle boundaries with misorientation of $\theta \geq 15^{\circ}$. The mechanical properties of processed samples were evaluated by means of isothermal tensile tests at ambient and elevated temperatures up to $973 \mathrm{~K}$ by using flat specimens with a gauge length of $12 \mathrm{~mm}$ and cross section of $3.0 \times 1.5 \mathrm{~mm}^{2}$. The specimens were heated/held at a test temperature during $15 \mathrm{~min}$ using tensile devise, which has been preheated to the desired temperature.

\section{Results and discussion}

\subsection{Deformation microstructures}

Typical microstructures that developed by multiple warm bar rolling to a total strain of 2 at different temperatures ranging from 773 to $1173 \mathrm{~K}$ are shown in Fig. 1. The starting microstructure is also shown in Fig. 1a for a reference. The developed deformation microstructures depend substantially on the rolling temperature. The microstructure that evolves during rolling at the lowest studied temperature of $773 \mathrm{~K}$ within the studied domain is characterized by an elongation of original grains along the rolling axis and corresponding axial alignment of strain-induced grain boundaries (Fig. 1b). As a result, the developed microstructure consists of highly elongated grains with the mean transverse grain size of $0.85 \mu \mathrm{m}$. The presence of well developed spatial subboundary net, some portions in which exhibit high-angle misorientations and look like incomplete grain boundaries in the grain interiors, is indicative of continuous DRX as the main mechanism responsible for the microstructure evolution at $773 \mathrm{~K}$. An increase in the rolling temperature to $973 \mathrm{~K}$ results in an increase in the transverse grain size to $1.2 \mu \mathrm{m}$ that developed at a total strain of 2 (Fig. 1c). Similar to the microstructure developed by rolling at $773 \mathrm{~K}$, the deformation microstructure evolved at $973 \mathrm{~K}$ consists of highly elongated grains, which are interleaved with chains of the fine grains. Also, there are many separate incomplete grain boundaries of deformation origin in the grain interiors that is typical of continuous DRX [12,13], although the frequently corrugated grain boundaries suggest a possibility of partial contribution of discontinuous DRX to the development of new fine grains at boundaries of elongated grains. The microstructure that develops during rolling at $1173 \mathrm{~K}$ is clearly distinguished by rather large grains; the transverse grain size comprises $3.4 \mu \mathrm{m}$ (Fig. 1d). In contrast to the lamellar-type microstructures developed during rolling at lower temperatures, the steel sample subjected to rolling at $1173 \mathrm{~K}$ is characterized by almost equiaxed grains with sparse subboundaries in their interiors. Such equiaxed grains can result from discontinuous dynamic and post-dynamic recrystallization during interpass preheating to high temperature of $1173 \mathrm{~K}$ Therefore, the discontinuous recrystallization is considered as the main mechanism of microstructure evolution during rolling at the highest studied temperature of $1173 \mathrm{~K}$.

Since the flow stress can be expressed by a power law function of temperature-compensated strain rate, $Z=\dot{\varepsilon} \exp (-Q / R T)$, where $\dot{\varepsilon}$ is the strain rate, $Q$ is the activation energy, $\mathrm{R}$ and $\mathrm{T}$ are the universal gas constant and temperature, respectively [14,15], the mean grain size (D) developed by DRX at sufficiently large strains should also obey power law functions of $\mathrm{Z}$. The following relations have been obtained for discontinuous and continuous DRX domains, respectively, $\mathrm{D} \sim \mathrm{Z}^{-0.4}$ and $\mathrm{D} \sim \mathrm{Z}^{-0.1}[8,11]$. The relationship between the DRX grain size and the temperature-compensated strain rate is shown in Fig. 2 for the present steel along with some previously reported results [15-20]. The value of $Z$ around $10^{12} \mathrm{~s}^{-1}$ has been reported as a separation point between discontinuous and continuous DRX $[8,20]$. Namely, the discontinuous DRX takes place during hot working at $\mathrm{Z}<10^{12} \mathrm{~s}^{-1}$, whereas continuous DRX develops at $Z>10^{12} \mathrm{~s}^{-1}$. This conclusion has been drawn after studying a dispersed strengthened stainless steel $[20,21]$. The present results indicate that the DRX behavior may be alternated by the phase content. The present 316L-type steel is characterized by lowered number of dispersed particles. As a result, the grain size of this steel is larger and transition from discontinuous to continuous DRX occurs at higher $\mathrm{Z}$ than for particle-bearing steel. It can be concluded, therefore, that rolling of the present steel at $1173 \mathrm{~K}$ corresponds to hot working conditions, when the flow stress depends remarkably on the temperature and strain rate. In contrast, the rolling temperatures of $773-973 \mathrm{~K}$ correspond to continuous DRX domain, which is characterized by a quite weak temperature/strain rate dependence of the flow stress.

\subsection{Mechanical properties}

Representative engineering stress-strain curves obtained by tensile tests at different temperatures for the 316L-type austenitic stainless steel subjected to warm to hot rolling to a total strain of 2 are shown in Fig. 3; and the main tensile properties of the steel at various temperatures are listed in Table 1. Rolling at temperatures of $773-1173 \mathrm{~K}$ resulted in remarkable strengthening of the steel; and the strength increment increases with a decrease in the rolling temperature. The room temperature yield strength varies from $720 \mathrm{MPa}$ to $945 \mathrm{MPa}$ depending on the rolling temperature within the studied temperature range. Correspondingly, the strengthening is accompanied by a degradation of plasticity. The total elongation at room temperature decreases to about $10 \%$ as the rolling temperature decreases to $773 \mathrm{~K}$. Note that uniform elongation in this case does not exceed a couple of percents. Such tensile behavior is associated with the effect of the rolling temperature on the hardening ability during subsequent tensile tests. The steel sample subjected to rolling at relatively high temperature of $1173 \mathrm{~K}$ exhibits large strain hardening, which expands after yielding to $10 \%$ of elongation. In contrast, the tensile flow stress sharply increases to its maximum at about $2 \%$ of elongation followed by a necking and apparent softening until failure for the samples rolled at 773-973 K. The tensile strength of the steel decreases with an increase in the test temperature. It should be noted that this strength decrease with temperature is not accompanied by any increase in plasticity. Instead, the total and uniform elongations decrease with increasing the test temperature 

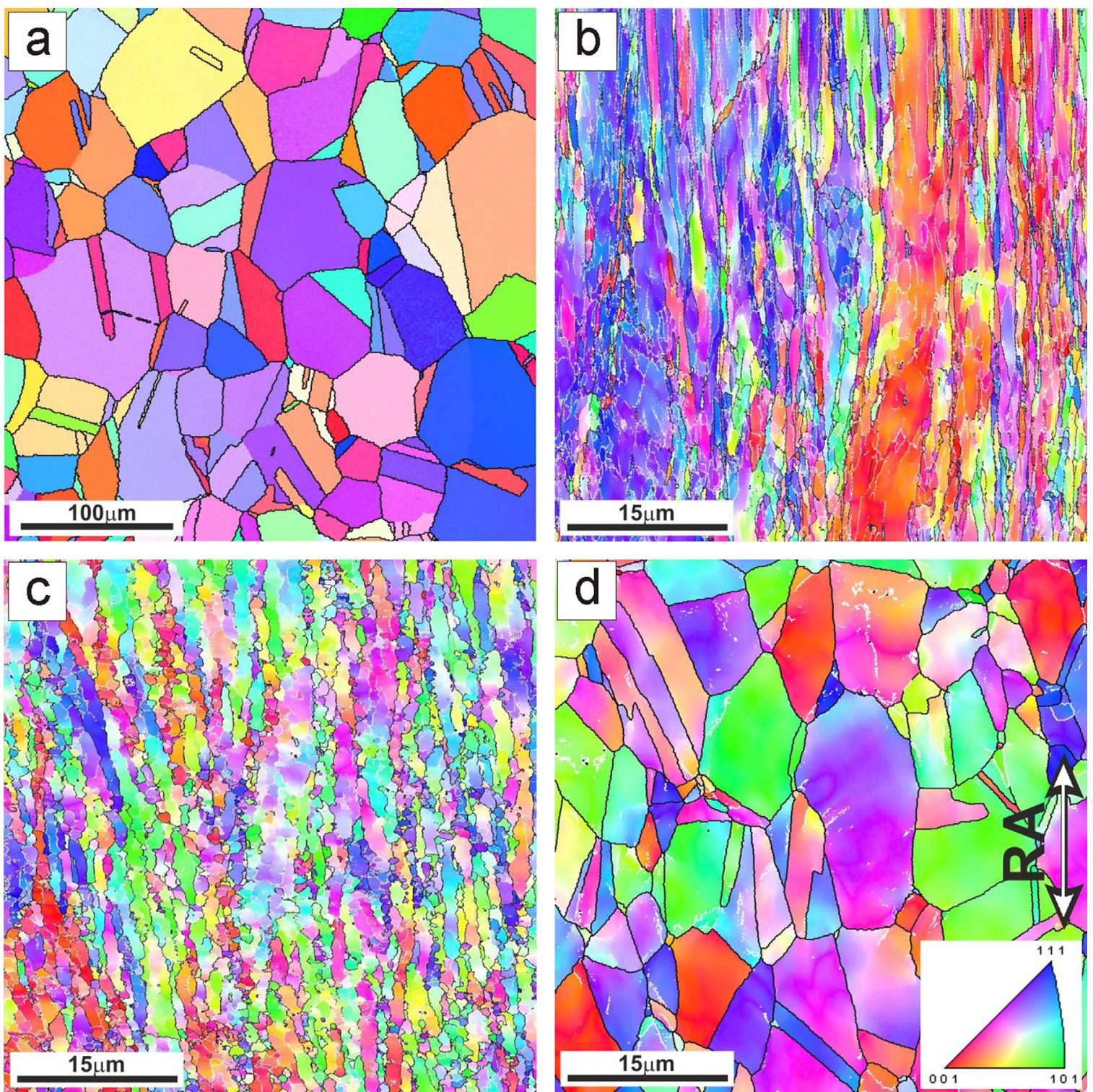

Fig. 1. Typical OIM micrographs of original microstructure (a) and deformation microstructures developed by rolling to a strain of 2 at temperatures of $773 \mathrm{~K}$ (b), $973 \mathrm{~K}$ (c) and $1173 \mathrm{~K}$ (d) of a 316L-type austenitic stainless steel. The high-angle boundaries and low-angle subboundaries are indicated by black and white lines, respectively. The inverse pole figures are shown for the rolling direction. The RA indicates the rolling axis.

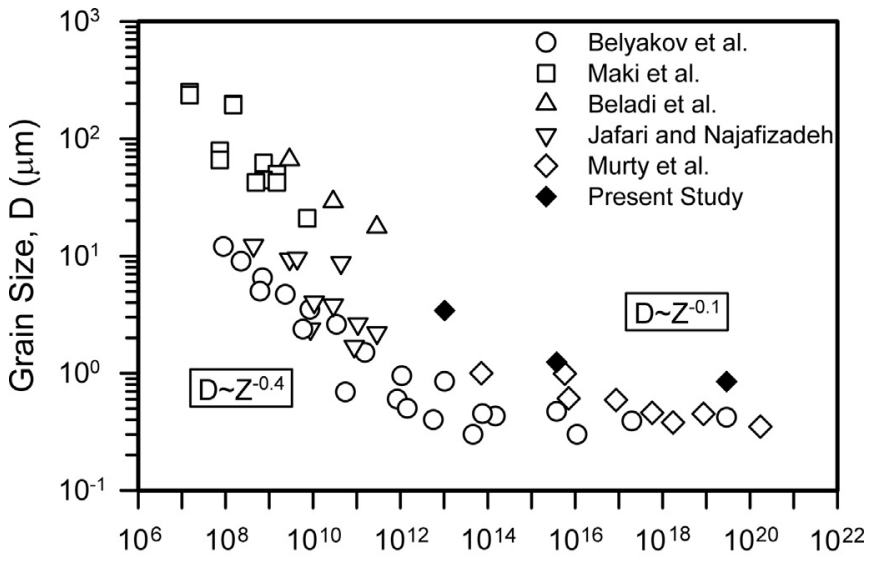

Temperature-Compensated Strain Rate, $Z\left(\mathrm{~s}^{-1}\right)$

Fig. 2. Relationship between the grains size evolved by warm to hot deformation and temperature compensated strain rate for the present 316L-type stainless steel (black symbols) and some reference steels (open symbols) [15-20]. in the range of 573-773 K. The elongations, which are comparable with those at room temperature, are observed at tensile tests at relatively high temperature of $973 \mathrm{~K}$.

The effect of the test temperature on the yield strength and ultimate tensile strength of the steel processed by warm rolling at different temperatures is represented in Figs. 4 and 5. Three regions with different temperature dependence of the tensile strength can be distinguished in Fig. 4. The tensile strength rapidly decreases with an increase in the test temperature form $293 \mathrm{~K}$ to $573 \mathrm{~K}$. Then, the temperature effect on the tensile strength becomes much smaller in the range of 573-873 K. Further increasing the test temperature above $873 \mathrm{~K}$ results in an accelerated decrease in the tensile strength irrespective of the temperature of previous warm rolling. Almost the same temperature dependence of strength properties was reported for S304H austenitic stainless steel processed by rolling under similar conditions [22]. The apparent strengthening at intermediate temperatures from $573 \mathrm{~K}$ to $873 \mathrm{~K}$ has been ascribed to the effects associated with dynamic strain aging [23], although this interesting phenomenon deserves more detailed investigation, because the present steel does not 


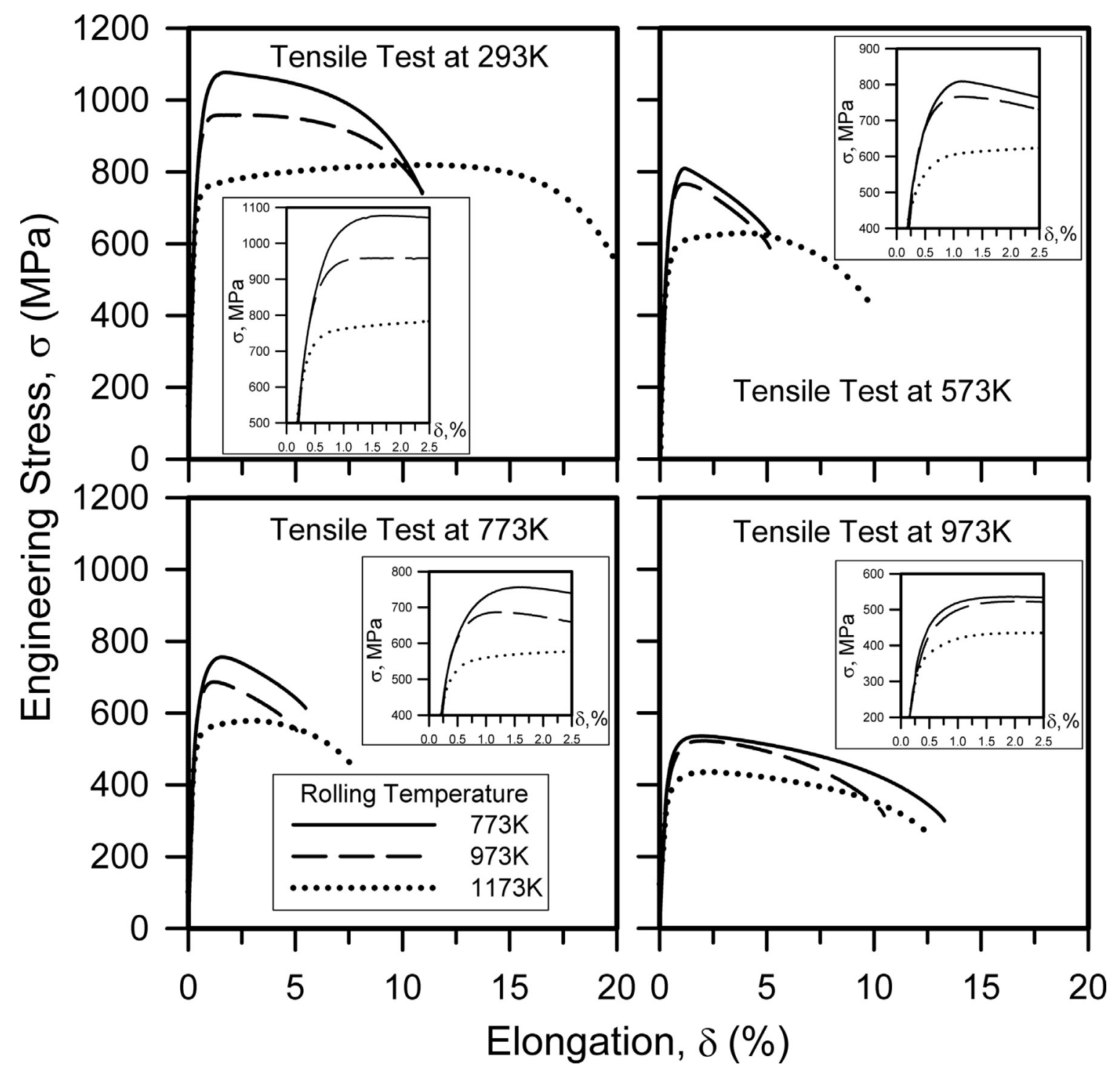

Fig. 3. Tensile stress-strain curves obtained at different testing temperatures for a 316L stainless steel subjected to warm rolling.

Table 1

Effect of the rolling temperature (RT) and tensile test temperature $\left(\mathrm{T}_{\text {test }}\right)$ on the yield strength $\left(\sigma_{0.2}\right)$, ultimate tensile strength (UTS) and total elongation $(\delta)$ of the austenitic stainless steel.

\begin{tabular}{lrllr}
\hline T test, K & RT, K & $\boldsymbol{\sigma}_{\mathbf{0 . 2}}, \mathbf{M P a}$ & $\mathbf{U T S}, \mathbf{M P a}$ & $\boldsymbol{\delta}, \boldsymbol{\%}$ \\
\hline 293 & 773 & 945 & 1080 & 10.5 \\
293 & 973 & 875 & 960 & 11.5 \\
293 & 1173 & 720 & 820 & 20.0 \\
573 & 773 & 725 & 810 & 4.5 \\
573 & 973 & 700 & 765 & 5.0 \\
573 & 1173 & 560 & 630 & 9.5 \\
773 & 773 & 660 & 755 & 5.0 \\
773 & 973 & 640 & 685 & 4.5 \\
773 & 1173 & 520 & 580 & 7.0 \\
873 & 773 & 585 & 645 & 5.5 \\
873 & 973 & 580 & 670 & 5.5 \\
873 & 1173 & 475 & 540 & 6.0 \\
973 & 773 & 460 & 535 & 13.0 \\
973 & 973 & 430 & 520 & 10.0 \\
973 & 1173 & 395 & 435 & 11.5 \\
\hline
\end{tabular}

exhibit any evidence for dynamic strain aging. The drastic decrease in the tensile strength at elevated temperatures above $873 \mathrm{~K}$ can attributed to the change in deformation mechanisms that is associated with a contribution of thermally activated processes [24]. The flow stress exhibits quite weak temperature and strain rate dependence in the range of relatively low temperatures below about $873 \mathrm{~K}$, i.e., athermic deformation domain. In contrast, the flow stress demonstrates a strong dependence on the temperature and strain rate during hot deformation at high temperatures, when the plastic flow is significantly affected by thermally activated processes. The change in the yield stress at elevated temperatures has been shown to be enhanced with a decrease in the grain size to micron/submicron scale $[25,26]$.

Analogous discussion can be applied for the effect of rolling temperature on the tensile strength in Fig. 5. The change of the rolling temperature from $773 \mathrm{~K}$ to $973 \mathrm{~K}$ does not substantially change the tensile strength, whereas further increase in the rolling temperature to $1173 \mathrm{~K}$ results in drastic decrease in the strength, especially, for tensile tests at temperatures of 273-873 K. Rolling at 773-973 K corresponds to warm working conditions (Fig. 2), which are characterized by weak dependencies of grain size and flow stress on deformation temperature. In other words, the temperature variation in the range of warm deformation does not significantly alter the strength of the processed steel. On the other hand, the flow stress and grain size depend radically on the deformation temperature under hot working (in the range of 


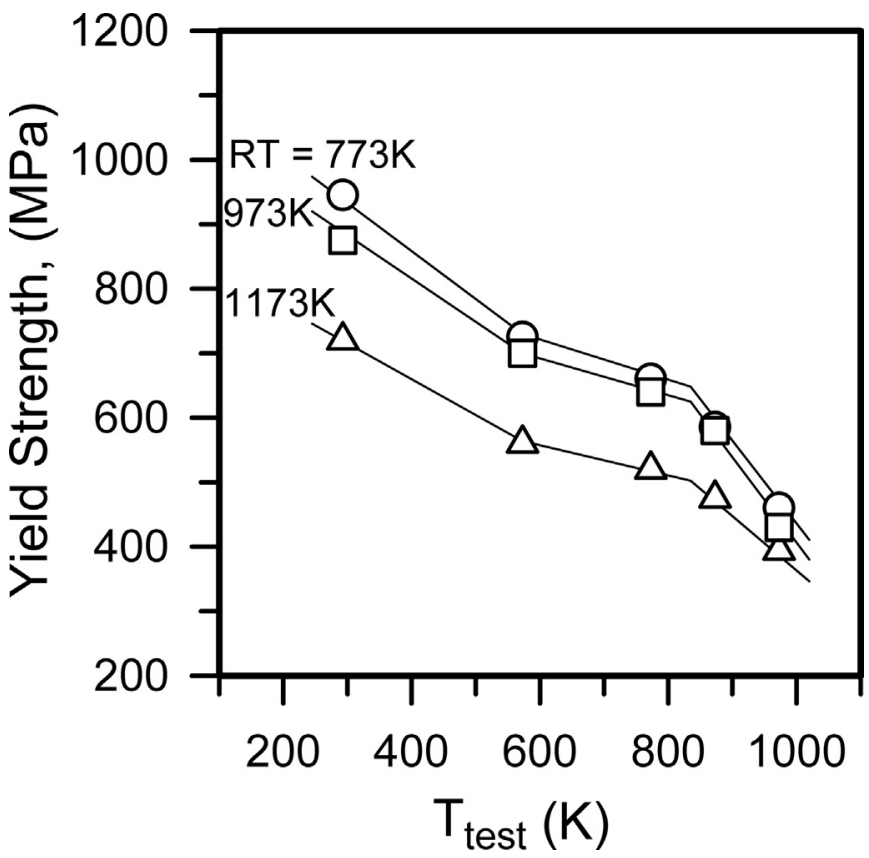

Fig. 4. Effects of the rolling temperature (RT) and tensile tests temperature $\left(T_{\text {test }}\right)$ on the yield strength.

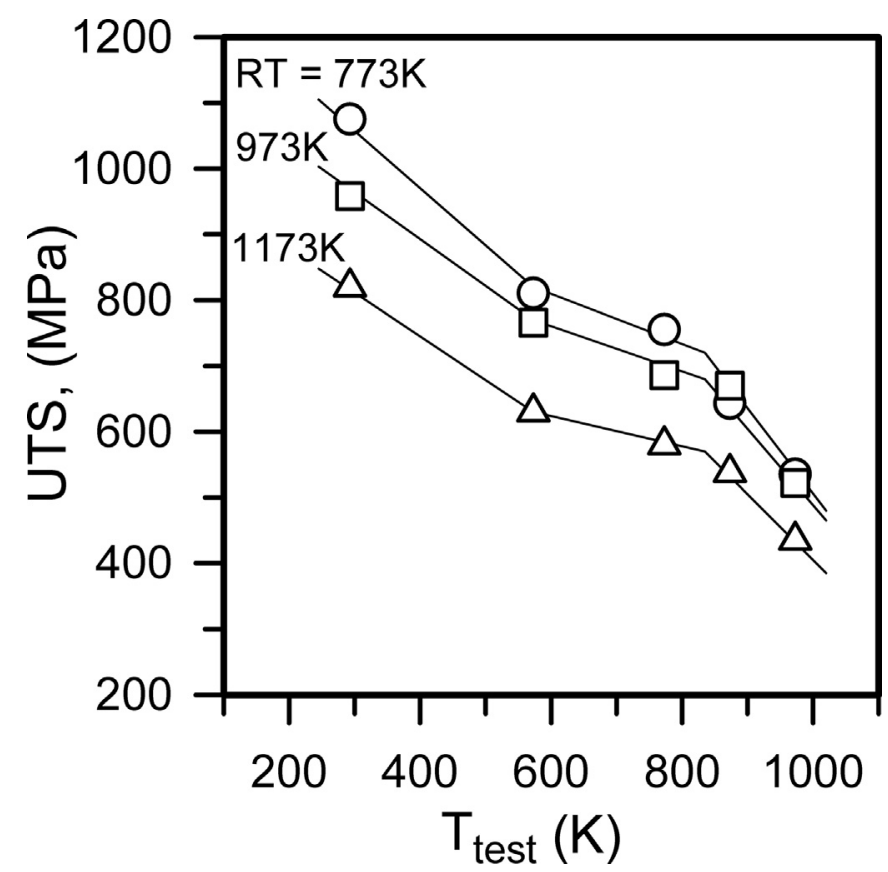

Fig. 5. Effects of the rolling temperature (RT) and tensile tests temperature $\left(T_{\text {test }}\right)$ on the ultimate tensile strength (UTS).

discontinuous DRX in Fig. 2). The highest studied rolling temperature of $1173 \mathrm{~K}$ falls in domain of discontinuous DRX and, therefore, the change in the rolling temperature from $973 \mathrm{~K}$ to $1173 \mathrm{~K}$ is accompanied by a substantial decrease in the low stress and strengthening.

The relationship between the yield strength and the transverse grain size that developed in the warm rolled steel is shown in Fig. 6. It is clearly seen that the yield strength of the rolled steel can be expressed by a linear function of inverse square root of the grain size that is much similar to Hall-Petch type relationship [2731]:

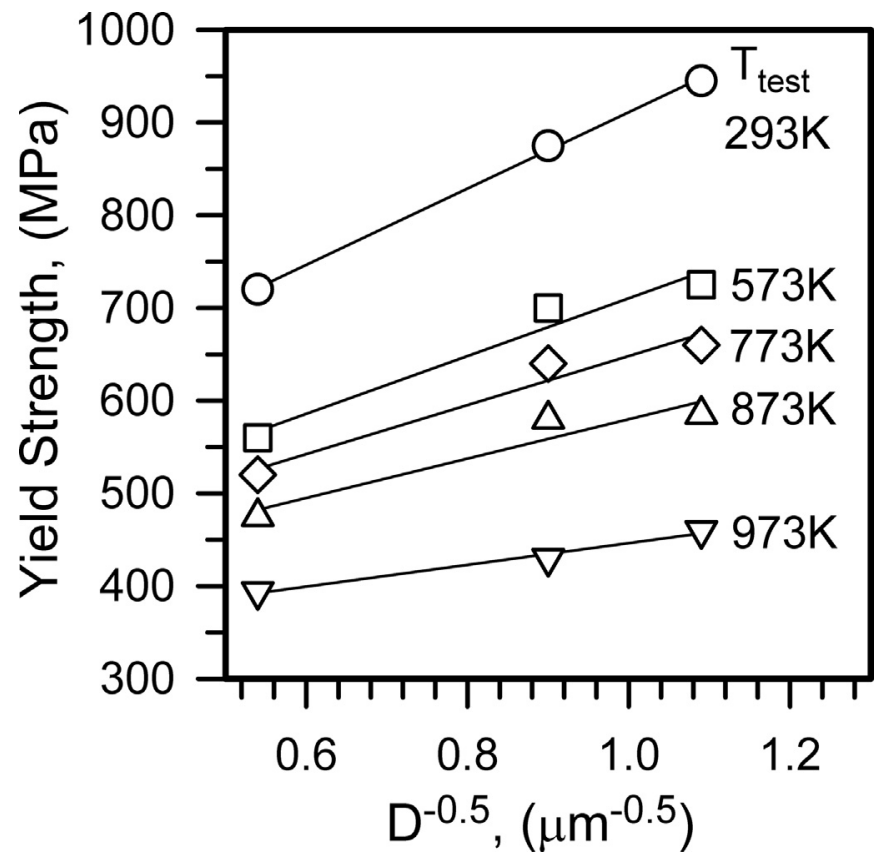

Fig. 6. Relationship between the transverse grain size (D) and the yield strength obtained by the isothermal tensile tests at various temperatures.

Table 2

Parameters of Hall-Petch type equation for various temperatures of tensile test.

\begin{tabular}{lll}
\hline $\mathbf{T}_{\text {test }}, \mathbf{K}$ & $\boldsymbol{\sigma}_{\boldsymbol{\varepsilon}}, \mathbf{M P a}$ & $\mathbf{k}_{\boldsymbol{\varepsilon}}, \mathbf{M P a} \boldsymbol{\mu \mathbf { m } ^ { \mathbf { 0 . 5 } }}$ \\
\hline 293 & 450 & 412 \\
573 & 400 & 312 \\
773 & 385 & 265 \\
873 & 370 & 212 \\
973 & 315 & 138 \\
\hline
\end{tabular}

$\sigma_{0.2}=\sigma_{\varepsilon}+\mathrm{k}_{\varepsilon} \mathrm{D}^{-0.5}$

where parameter of $\sigma_{\varepsilon}$ includes Peierls stress, solid solution strengthening and work hardening, and $\mathrm{k}_{\varepsilon}$ is a grain size strengthening factor. The experimental constants of $\sigma_{\varepsilon}$ and $k_{\varepsilon}$ obtained from Fig. 6 are represented in Table 2 for various tensile test temperatures. Both $\sigma_{\varepsilon}$ and $k_{\varepsilon}$ decreases with an increase in the test temperature that is similar to other studies on the temperature dependence of Hall-Petch type relationship [25,32,33]. Generally, these parameters in Hall-Petch type equation are functions of shear modulus (G). Therefore, the temperature effect on the tensile strength may be attributed to the temperature dependence of the shear modulus. Taking into account the temperature dependence of the shear modulus [24], the normalized by shear modulus values of the yield strengths and parameters of Hall-Petch type equation are shown in Fig. 7. The temperature effect on the yield strength becomes less pronounced after dividing the strength by shear modulus (cf. Figs. 6 and 7). It is interesting that $\sigma_{\varepsilon} / G$ seems to be independent of temperature. This suggests that variations in Peierls stress, solid solution and dislocation strengthening with temperature are mainly associated with a temperature dependence of shear modulus. In contrast, the grain size strengthening factor exhibits much stronger temperature dependence than the shear modulus. Various commonly accepted models of dislocation pile-up or grain-boundary dislocations predict the grain size strengthening factor from $\mathrm{k}_{\varepsilon} \sim \mathrm{G}^{0.5}$ to $\mathrm{k}_{\varepsilon} \sim \mathrm{G}[3,4,33,34]$. The present results in Fig. 7 imply that the grain boundary ability to accommodate plastic flow is characterized by a 


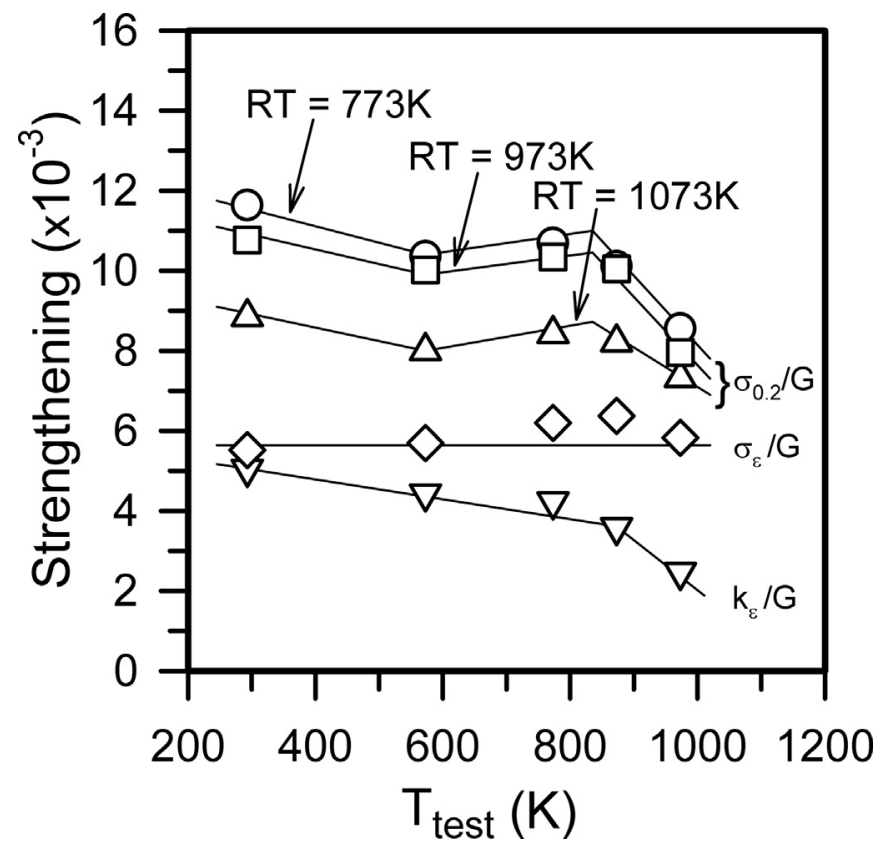

Fig. 7. Effect of the test temperature on the strengthening normalized by shear modulus, i. e., $\sigma_{0.2} / \mathrm{G}, \sigma_{\varepsilon} / \mathrm{G}, \mathrm{k}_{\varepsilon} / \mathrm{G}$.

more complicated temperature dependence, which cannot be explained in the framework of the existing models and should be clarified by further investigations.

\section{Conclusions}

The deformation microstructures and tensile behavior of a 316L-type austenitic stainless steel subjected to multiple warm rolling to total strains of 2 at $773-1173 \mathrm{~K}$ were studied. The main results are summarized as follows.

1. The multiple bar rolling was accompanied by substantial grain refinement. The transverse grain size decreased from $3.4 \mu \mathrm{m}$ to $0.85 \mu \mathrm{m}$ as the rolling temperature decreased from $1173 \mathrm{~K}$ to $773 \mathrm{~K}$. The finally evolved microstructures in the samples subjected to multiple rolling at $1173 \mathrm{~K}$ resulted from discontinuous DRX followed by post-dynamic recrystallization, whereas continuous DRX was mainly responsible for the microstructure evolution at lower rolling temperatures.

2. The rolled steel samples were characterized by significant strengthening as revealed by tensile tests at temperatures ranging from $293 \mathrm{~K}$ to $973 \mathrm{~K}$. A decrease in the rolling temperature from $1173 \mathrm{~K}$ to $773 \mathrm{~K}$ increased the yield strength from $720 \mathrm{MPa}$ to $945 \mathrm{MPa}$ and from $395 \mathrm{MPa}$ to $470 \mathrm{MPa}$ at $293 \mathrm{~K}$ and $973 \mathrm{~K}$, respectively.

3. The yield strength of the steel samples subjected to the multiple warm rolling obeys the following Hall-Petch type relationship:

$\sigma_{0.2}=\sigma_{\varepsilon}+\mathrm{k}_{\varepsilon} \mathrm{D}^{-0.5}$

where $\mathrm{D}$ is the transverse grain size and constants of $\sigma_{\varepsilon}$ and $\mathrm{k}_{\varepsilon}$ depend on temperature. With an increase in the tensile test temperature from $293 \mathrm{~K}$ to $973 \mathrm{~K}$, the first term of $\sigma_{\varepsilon}$ decreases from $450 \mathrm{MPa}$ to $315 \mathrm{MPa}$ that corresponds to the temperature dependence of the shear modulus, while $k_{\varepsilon}$ exhibits much stronger temperature dependence, i.e., it decreases from $412 \mathrm{MPa} \mu \mathrm{m}^{0.5}$ to $138 \mathrm{MPa} \mu \mathrm{m}^{0.5}$.

4. The multiple bar rolling to large total strains of about 2 is effective method for processing austenite stainless steels with enhanced yield strength.

\section{Acknowledgement}

This study was supported by Ministry of Education and Science, Russia, under Grant No. 14.575.21.0092 (ID No. RFMEFI57514X0092). The authors are grateful to the personnel of the Joint Research Centre, Belgorod State University, for their assistance with instrumental analysis.

\section{References}

[1] K.H. Lo, C.H. Shek, J.K.L. Lai, Recent developments in stainless steels, Mater. Sci. Eng. R. 65 (2009) 39-104.

[2] W. Martienssen, H. Warlimont, Springer Handbook of Condensed Matter and Materials Data, Springer, Berlin, Germany, 2005.

[3] E.O. Hall, The deformation and ageing of mild steel: II characteristics of the Lüders deformation, Proc. Phys. Soc. B 64 (1951) 742-747.

[4] R. Armstrong, I. Codd, R.M. Douthwaite, N.J. Petch, The plastic deformation of polycrystalline aggregates, Philos. Mag. 7 (1962) 45-58.

[5] C.M. Young, O.D. Sherby, Subgrain formation and subgrain-boundary strengthening in iron-based materials, J. Iron Steel Inst. 211 (1973) 640-647.

[6] B.P. Kashyap, K. Tangri, On the Hall-Petch relationship and substructural evolution in type 316L stainless steel, Acta Metall. Mater. 43 (1995) 3971-3981.

[7] S. Takaki, D. Akama, N. Nakada, T. Tsuchiyama, Effect of grain boundary segregation of interstitial elements on Hall-Petch coefficient in steels, Mater Trans. 55 (2014) 28-34.

[8] M. Tikhonova, A. Belyakov, R. Kaibyshev, Strain-induced grain evolution in an austenitic stainless steel under warm multiple forging, Mater. Sci. Eng. A 564 (2013) 413-422.

[9] T. Sakai, A. Belyakov, R. Kaibyshev, H. Miura, J.J. Jonas, Dynamic and post-dynamic recrystallization under hot, cold and severe plastic deformation conditions, Prog. Mater. Sci. 60 (2014) 130-207.

[10] Z. Yanushkevich, A. Belyakov, R. Kaibyshev, Microstructural evolution of a 304type austenitic stainless steel during rolling at temperatures of 773-1273 K, Acta Mater. 82 (2015) 244-254.

[11] A. Belyakov, Z. Yanushkevich, M. Tikhonova, R. Kaibyshev, On regularities of grain refinement through large strain deformation, Mater. Sci. Forum 838-839 (2016) 314-319.

[12] A. Belyakov, W. Gao, H. Miura, T. Sakai, Strain-induced grain evolution in polycrystalline copper during warm deformation, Metall. Mater. Trans. A 29 (1998) 2957-2965.

[13] A. Belyakov, T. Sakai, H. Miura, Fine-grained structure formation in austenitic stainless steel under multiple deformation at $0.5 \mathrm{Tm}$, Mater. Trans. JIM 41 (2000) 476-484.

[14] H.J. McQueen, J.J. Jonas, Recovery and recrystallization during high temperature deformation, in: R.J. Arsenault (Ed.), Treatise on Materials Science and Technology, Academic Press, New York, 1975, pp. 394-490.

[15] T. Maki, K. Akasaka, K. Okuno, I. Tamura, Dynamic recrystallization of austenite in 18-8 stainless steel and $18 \mathrm{Ni}$ maraging steel, Trans. Iron Steel Ins. Jpn. 22 (1982) 253-261.

[16] A. Belyakov, T. Sakai, H. Miura, R. Kaibyshev, Grain refinement under multiple warm deformation in 304 type austenitic stainless steel, ISIJ Int. 39 (1999) 592-599.

[17] M. Jafari, A. Najafizadeh, Correlation between Zener-Hollomon parameter and necklace DRX during hot deformation of 316 stainless steel, Mater. Sci. Eng. A 501 (2009) 16-25.

[18] H. Beladi, P. Cizek, P.D. Hodgson, On the characteristics of substructure development through dynamic recrystallization, Acta Mater. 58 (2010) 3531-3541.

[19] S.V.S. Murty, S. Torizuka, K. Nagai, T. Kitai, Y. Kogo, Effect of initial grain size on evolved ferrite grain size during high Z large strain deformation, Mater. Sci. Technol. 26 (2010) 879-885.

[20] A. Belyakov, M. Tikhonova, Z. Yanushkevich, R. Kaibyshev, Regularities of grain refinement in an austenitic stainless steel during multiple warm working, Mater. Sci. Forum 753 (2013) 411-416.

[21] Z. Yanushkevich, A. Mogucheva, M. Tikhonova, A. Belyakov, R. Kaibyshev, Structural strengthening of an austenitic stainless steel subjected to warm-tohot working, Mater. Charact. 62 (2011) 432-437.

[22] Z. Yanushkevich, A. Belyakov, R. Kaibyshev, Mechanical properties at elevated temperatures of an $\mathrm{S} 304 \mathrm{H}$-type austenitic stainless steel processed by warm rolling, Adv. Mater. Res. 922 (2014) 844-849.

[23] B.K. Choudhary, Influence of strain rate and temperature on tensile 
deformation and fracture behavior of type $316 \mathrm{~L}(\mathrm{~N})$ austenitic stainless steel, Metall. Mater. Trans. A 45 (2014) 302-316.

[24] H.J. Frost, M.F. Ashby, Deformation Mechanism Maps, Pergamon Press, Oxford, UK, 1982.

[25] V. Kutumba Rao, D.M.R. Taplin, P. Rama Rao, The grain size dependence of flow and fracture in a Cr-Mn-N austenitic steel from 300 to $1300 \mathrm{~K}$, Metall. Trans. A 6 (1975) 77-86.

[26] J.H. Schneibel, M. Heilmaier, W. Blum, G. Hasemenn, T. Shanmugasundaram, Temperature dependence of the strength of fine- and ultrafine-grained materials, Acta Mater. 59 (2011) 1300-1308.

[27] N. Hansen, Hall-Petch relation and boundary strengthening, Scr. Mater. 51 (2004) 801-806.

[28] X. Huang, S. Morito, N. Hansen, T. Maki, Ultrafine structure and strength in cold-rolled martensite, Metall. Mater. Trans. A 43 (2012) 3517-3531.

[29] I. Shakhova, V. Dudko, A. Belyakov, K. Tsuzaki, R. Kaibyshev, Effect of large strain cold rolling and subsequent annealing on microstructure and mechanical properties of an austenitic stainless steel, Mater. Sci. Eng. A 545
(2012) 176-186.

[30] M.M. Abramova, N.A. Enikeev, R.Z. Valiev, A. Etienne, B. Radiguet, Y. Ivanisenko, X. Sauvage, Grain boundary segregation induced strengthening of an ultrafine-grained austenitic stainless steel, Mater. Lett. 136 (2014) 349-352.

[31] M. Odnobokova, A. Belyakov, R. Kaibyshev, Development of nanocrystalline 304L stainless steel by large strain cold working, Metals 5 (2015) 656-668.

[32] K.K. Singh, S. Sangal, G.S. Murty, Hall-Petch behaviour of 316L austenitic stainless steel at elevated temperatures, Mater. Sci. Technol. 18 (2002) 1168-1178.

[33] K. Kawasaki, T. Tsuchiyama, S. Takaki, Temperature dependence of Hall-Petch relationship in ultra fine grained iron. in: Proceedings of the 2nd International Symposium on Ultra-fine Grained Structures, Geelong, Australia, 11-13 November 2003, The Institute of Materials Engineering Australasia Ltd., Australia, 2003, Paper No. 42.

[34] J.C.M. Li, Y.T. Chou, The role of dislocations in the flow stress grain size relationships, Metall. Trans. 1 (1970) 1145-1159. 